03,05

\title{
Гальваномагнитные свойства поликристаллического селенида марганца $\mathrm{Gd}_{0.2} \mathrm{Mn}_{0.8} \mathrm{Se}$
}

\author{
(C) О.Б. Романова ${ }^{1,2}$, С.С. Аплеснин ${ }^{1,2}$, А.М. Харьков ${ }^{2}$, А.Н. Масюгин $^{2}$, К.И. Янушкевич ${ }^{3}$ \\ ${ }^{1}$ Институт ффизики им. Л.В. Киренского, ФИЦ КНЦ СО РАН, \\ Красноярск, Россия \\ ${ }^{2}$ Сибирский государственный аэрокосмический университет им. акад. М.Ф. Решетнева, \\ Красноярск, Россия \\ ${ }^{3}$ НПЦ НАН Беларуси по материаловедению, \\ Минск, Беларусь \\ E-mail: rob@iph.krasn.ru
}

(Поступила в Редакцию 12 января 2017 г.)

\begin{abstract}
Проведены исследования электрических и гальваномагнитных свойств твердого раствора $\mathrm{Gd}_{0.2} \mathrm{Mn}_{0.8} \mathrm{Se}$ в нулевом и магнитном поле $13 \mathrm{kOe}$ в интервале температур $80-400 \mathrm{~K}$. Найдено отрицательное магнитосопротивление ниже комнатных температур и гистерезис вольт-амперных характеристик. Установлена смена знака магнитосопротивления и коэффициента термоэдс с ростом температуры. Определены типы носителей тока из константы Холла и найдено отличие знаков коэффициентов термоэдс и Холла при высоких температурах. Экспериментальные данные объясняются в модели орбитального упорядочения и спин-орбитального взаимодействия.
\end{abstract}

Исследование выполнено при финансовой поддержке РФФИ, правительства Красноярского края, Красноярского краевого фонда поддержки научной и научно-технической деятельности в рамках научного прокта № 17-42-240079 р_сибирь_а и РФФИ № 16-52-00045 Бел_а.

DOI: 10.21883/FTT.2017.07.44589.003

\section{1. Введение}

Создание магнитных полупроводников для элементной базы в микроэлектронике, в частности спинтронике, способных работать в широком диапазоне температур, представляет интерес как с фундаментальной, так и прикладной точки зрения. Принцип работы спинтронных устройств основан на эффекте магнитосопротивления. Халькогениды переходных металлов и их твердые растворы оказались хорошими модельными объектами для изучения этого эффекта. В результате исследований моносульфида марганца и синтезированных на его основе твердых растворов с катионным замещением $3 d$-элементами ( $\mathrm{Fe}, \mathrm{Cr}, \mathrm{Co}$ и т.д.) [1] и $4 f$-элементами $(\mathrm{Gd}, \mathrm{Yb}, \mathrm{Sm}$ и т.д.) [2,3] был обнаружен эффект магнитосопротивления и переход металл-диэлектрик при изменении концентрации замещения, магнитного поля и температуры.

В сульфидах марганца $\mathrm{Gd}_{x} \mathrm{Mn}_{1-x} \mathrm{~S}$ обнаружена смена знака магнитосопротивления с положительного на отрицательный и найден его максимум в области перехода в магнитоупорядоченное состояние для двух составов вблизи концентрации протекания $x_{c}=0.16$ [4]. Установлен рост диэлектрической проницаемости, а также магнитоемкостный эффект [5]. В селениде марганца при анионном замещении обнаружено отрицательное магнитосопротивление выше температуры Нееля до комнатных температур [6]. В связи с этим синтез нового халькогенидного соединения при катионном замещении марганца гадолинием в системе $\mathrm{MnSe}$ позволит выяс- нить влияние анионной системы в результате исследования его транспортных и гальваномагнитных свойств с концентрацией в области протекания ионов гадолиния по решетке $x=0.2$.

Исходный моноселенид марганца является антиферромагнитным полупроводником $p$-типа, имеет структуру гранецентрированной кубической (ГЦК) решетки c кубической элементарной ячейкой $[7,8]$. Результаты комплексных исследований электрических и оптических свойств показали, что для $\mathrm{MnSe}$ ширина запрещенной зоны может иметь величину $E_{g}=2.30 \mathrm{eV}$ [9]. При охлаждении и нагревании $\mathrm{MnSe}$ в температурном поведении сопротивления наблюдается гистерезис в температурном интервале $125<T<260 \mathrm{~K}$, обусловленный сосуществованием кубической и гексагональной модификаций. Температура магнитного фазового перехода, определенная по данным нейтронографических исследований $[10]$, для $\mathrm{MnSe}$ в кубической модификации равна $T_{N}=135 \mathrm{~K}$, а в гексагональной фазе NiAs она совпадает с температурой структурного перехода $T_{s}=272 \mathrm{~K}$. B MnSe [11] сопротивление падает с ростом внешнего магнитного поля.

Селенид гадолиния перспективный и широкоприменяемый материал в производстве радиоизотопных источников энергии. Соединение GdSe обнаруживает металлический тип проводимости, при низких температурах $50 \mathrm{~K}$ переходит в магнитоупорядоченное состояние антиферромагнитного типа [12]. Кристаллизуется в кубической структуре типа $\mathrm{NaCl}$ с параметром элементарной 
ячейки $0.5775 \mathrm{~nm}$. Замещение катионов марганца ионами редкоземельных элементов приводит к электронному допированию и образованию дополнительных обменных ферромагнитных взаимодействий между ионами марганца, в результате кинетического $s-d$-взаимодействия. Ожидаются изменения магнитной структуры и усиления ферромагнитных свойств, изменение типа проводимости, носителей тока и обнаружение магниторезистивного эффекта.

Цель настоящей работы - установить влияние анионной подсистемы на гальваномагнитные свойства в области протекания по концентрации редкоземельного иона, в том числе изменение транспортных характеристик в магнитном поле для замещенных селенидов.

\section{2. Результаты эксперимента и их обсуждение}

Твердые растворы $\mathrm{Gd}_{x} \mathrm{Mn}_{1-x} \mathrm{Se}(x=0.2)$ получены методом твердофазной реакции, описанной в работе [13], из порошков исходных соединений в вакуумированных кварцевых ампулах в однозонной печи сопротивления.

Определение фазового состава и кристаллической структуры образцов $\mathrm{Gd}_{x} \mathrm{Mn}_{1-x} \mathrm{Se}$ проведено при $300 \mathrm{~K}$ на рентгеновской установке ДРОН-3 с использованием $\mathrm{Cu} K_{\alpha}$-излучения. Данные рентгеноструктурного анализа показали, что синтезированные соединения обладают ГЦК-структурой типа $\mathrm{NaCl}$, типичной для моноселенида марганца. С увеличением степени катионного замещения $(x)$ параметр элементарной ячейки $a$ увеличивается от $a=0.5440 \mathrm{~nm}$ для $\mathrm{MnSe}$ до $a=0.5520 \mathrm{~nm}$ для $\mathrm{Gd}_{0.2} \mathrm{Mn}_{0.8} \mathrm{Se}$ в соответствии с возрастанием ионного радиуса замещающего элемента $(r=0.83 \AA$ для $\mathrm{Mn}$, $r=0.94 \AA$ для $\mathrm{Gd})$. Исследуемые соединения с концентрацией замещения $x=0.2$ являются антиферромагнетиками с температурой Нееля $T_{N}=80 \mathrm{~K}$ и парамагнитной температурой Кюри $\Theta$, имеющей отрицательное значение и убывающей по абсолютной величине относительно исходного соединения $(-350 \mathrm{~K}$ для $x=0$ до $-86 \mathrm{~K}$ для $x=0.2)$, что свидетельствует об увеличении ферромагнитных корреляций с ростом концентрации гадолиния [13]. Усиление ферромагнитных корреляций подтверждается изменениями в поведении удельного электросопротивления, магнитосопротивления и эффекта Холла.

Измерение удельного электросопротивления было проведено четырехзондовым методом в нулевом магнитном поле и поле $13 \mathrm{kOe}$, направленном перпендикулярно току. Результаты электрических измерений представлены на рис. 1. Поведение температурной зависимости удельного электросопротивления для образца $\mathrm{Gd}_{0.2} \mathrm{Mn}_{0.8} \mathrm{Se}$ указывает на полупроводниковый характер проводимости, аналогично MnSe [11,14]. По наклону прямолинейной части зависимости $\lg \rho(1 / T)$ определена ширина запрещенной зоны $\Delta E$, которая составляет $\sim 0.3 \mathrm{eV}$ и в магнитном поле не меняется. Наблюдается

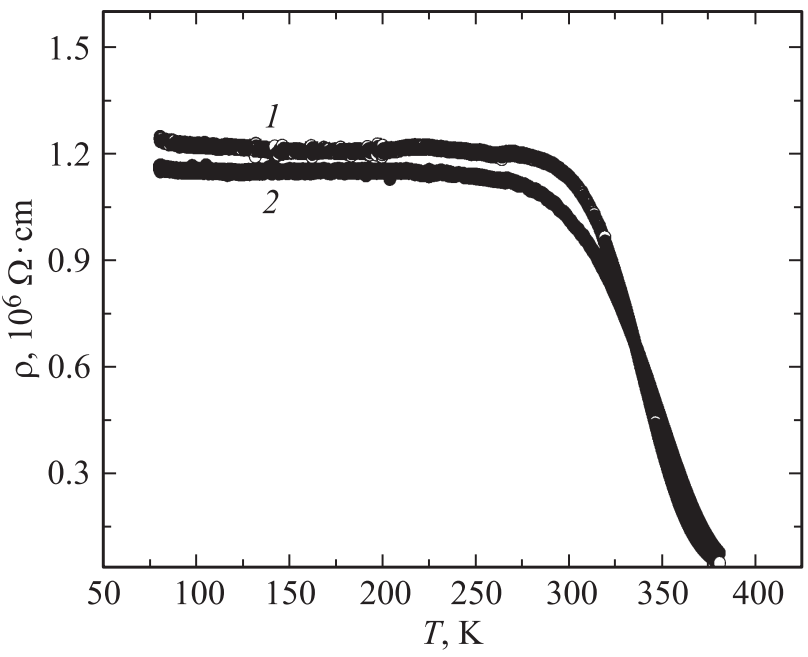

Рис. 1. Температурные зависимости электросопротивления в нулевом магнитном поле (1) и поле $13 \mathrm{kOe}(2)$ системы $\mathrm{Gd}_{x} \mathrm{Mn}_{1-x} \operatorname{Se} \mathrm{c} x=0.2$.

уменьшение значения $\rho$ в образце $\mathrm{Gd}_{0.2} \mathrm{Mn}_{0.8} \mathrm{Se}$ по сравнению с электросопротивлением исходного моноселенида марганца. Подобное поведение наблюдалось при замещении марганца в системе $\mathrm{MnS}$ ионами гадолиния [15]. Следует отметить, что при $T=250 \mathrm{~K}$ удельное электросопротивление практически не зависит от температуры. При дальнейшем увеличении температуры наблюдается экспоненциальное уменьшение сопротивления. Магнитосопротивление $\delta_{R}=(R(H)-R(0)) / R(0)$ в системе $\mathrm{Gd}-\mathrm{Mn}-\mathrm{Se}$ с концентрацией замещения $x=0.2$ меняет знак с ростом температуры при $T=320 \mathrm{~K}$. При этой температуре наблюдаются резкое уменьшение величины постоянной Холла, широкий гистерезис вольт-амперной характеристики $(\mathrm{BAX})$ и максимум на температурной зависимости коэффициента термоэдс.

Наличие отрицательного магнитосопротивления подтверждается ВАХ (рис. 2) поликристаллического образца $\mathrm{Gd}_{0.2} \mathrm{Mn}_{0.8} \mathrm{Se}$ в магнитных полях $H=0$ и $H=13 \mathrm{kOe}$. В магнитном поле гистерезис уменьшается. Замещение двухвалентного иона марганца трехвалентным ионом гадолиния приводит к перераспределению электронной плотности между $t_{2 g}$-состояниями $\mathrm{Mn}^{2+}$ и $\mathrm{Gd}^{3+}$ и $e_{g}$-состояниями. В результате сильных электронных корреляций на ближайших ионах марганца и на ионах гадолиния возникает орбитальное упорядочение. Ионы гадолиния протекают по решетке и имеют орбитальное упорядочение ферромагнитного типа, которое разбивается на домены. На интерфейсе $\mathrm{Mn}-\mathrm{Gd}$ существует сильное спин-орбитальное взаимодействие типа Рашбы [16]. В гадолиневой подсистеме орбитальный магнитный момент $\left(\left\langle L^{z}\right\rangle\right)$ на ионе поляризует электроны проводимости по спину, что приводит к расщеплению спектра электронных возбуждений на интерфейсе на величину $\left.2 \lambda\left\langle L^{z}\right\rangle\right) \sigma$, где $\lambda$ - параметр спин-орбитального взаимодействия $5 d$-электронов, $\sigma-$ спин электрона проводи- 

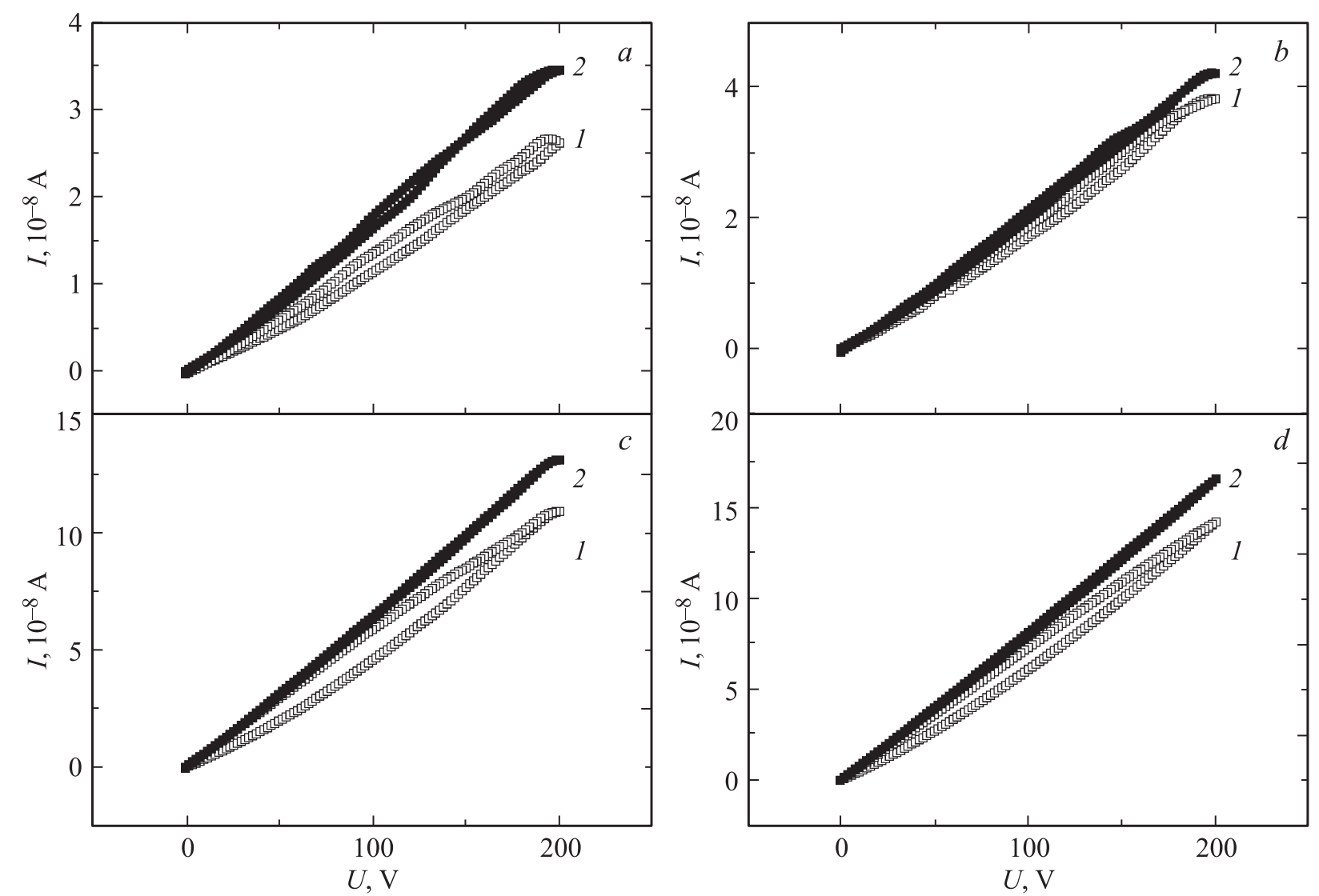

Рис. 2. Вольт-амперные характеристики, измеренные в нулевом (1) и магнитном поле $13 \mathrm{kOe}(2)$ для образца $\mathrm{Gd}_{0.2} \mathrm{Mn}_{0.8} \mathrm{Se}_{\text {при }}$ $T=80(a), 160(b), 200(c), 280 \mathrm{~K}(d)$.

мости. В магнитном поле домены с ориентацией орбитального момента против поля исчезают, и плотность доменов с угловыми моментами по полю растет. Это приводит к усилению тока проводимости $U_{\delta \text { max }}=40 \mathrm{~V}$, $U(d I / d U=\max )=50 \mathrm{~V}$ для $T=80 \mathrm{~K}$. Внешнее электрическое поле за счет кулоновского взаимодействия приводит к изменению импульса электрона, повороту вектора магнитного момента и слиянию доменов. Этим процессом обусловлен гистерезис ВАХ.

Магнитосопротивление $\delta_{R}=(R(H)-R(0)) / R(0)$ зависит от внешнего электрического поля и наблюдаются максимумы по абсолютной величине до $200 \mathrm{~K}$. Для некоторых температур $\delta_{R}$ представлено на рис. 3. Значения напряжений, при которых магнитосопротивление и производная $d I / d U$ достигают максимумов, близки по значению. Так, $U_{\delta \max }=40 \mathrm{~V}, U(d I / d U=\max )=50 \mathrm{~V}$ для $T=80 \mathrm{~K}, U_{\delta \max }=88 \mathrm{~V}, U(d I / d U=\max )=74 \mathrm{~V}$ для $T=160 \mathrm{~K}, U_{\delta \max }=184 \mathrm{~V}, U(d I / d U=\max )=184 \mathrm{~V}$ для $T=200 \mathrm{~K}$. Максимальные значения достигаются при изменении доменной структуры. В магнитоупорядоченной области уменьшение сопротивления в магнитном поле достигает 30-40\%. Это связано с образованием ферромагнитных областей (ферронов) в антиферромагнитной матрице. В магнитном поле размер феррона увеличивается, ширина потенциального барьера меж- ду ферронами уменьшается и подвижность носителей тока растет. Смена знака магнитосопротивления при $T=320 \mathrm{~K}$ вызвана снятием вырождения по направлению импульса электрона и его спина, т.е. величина расщепления в электронном спектре возбуждений по спину в модели Рашбы имеет величину порядка тепловой энергии. Рост сопротивления в магнитном поле связан с уменьшением подвижности носителей тока в подсистеме ионов гадолиния в результате орбитального упорядочения электронов [17].

Тип носителей заряда в катионзамещенных твердых растворах $\mathrm{Gd}_{x} \mathrm{Mn}_{1-x} \mathrm{Se}$ определим из холловских измерений. На рис. 4, $a$ представлены температурные зависимости коэффициента Холла образца $\mathrm{Gd}_{0.2} \mathrm{Mn}_{0.8} \mathrm{Se}$. Измерения коэффициента Холла проведены на постоянном токе в области температур 80-400 К. При измерении эффекта Холла были учтены вклады паразитных эдс, возникающие вследствие побочных гальваномагнитных и термомагнитных эффектов, а также асимметричность контактов. Замещение марганца гадолинием приводит к изменению типа носителей тока с дырочного, свойственного моноселениду марганца [18], к электронному для $\mathrm{Gd}_{0.2} \mathrm{Mn}_{0.8} \mathrm{Se}$. На температурной зависимости $R_{H}$ наблюдается участок, где постоянная Холла принимает положительные значения при $T=195-275 \mathrm{~K}$ (рис. 4,a). 
Появление участков с положительным значением $R_{H}$ на температурной зависимости коэффициента Холла связано, во-первых, с присутствием в твердых растворах $\mathrm{Gd}_{x} \mathrm{Mn}_{1-x} \mathrm{Se}$ носителей заряда разного знака; во-вторых, с ростом или уменьшением их количества при разных температурах и, в-третьих, с подвижностью носителей.

Согласно литературным данным [12], результаты исследований дифференциальной термоэдс монохалькогенидов трехвалентных редкоземельных элементов показали, что ее знак в большинстве случаев не совпадает со знаком постоянной Холла и ее температурная зависимость носит сложный характер. На рис. $4, b$ представлены температурные зависимости коэффициента термоэдс твердых растворов системы $\mathrm{Gd}_{x} \mathrm{Mn}_{1-x} \mathrm{Se}$ для концентрации $(x=0.2)$. Известно, что термоэдс является самым чувствительным кинетическим электронным свойством металла. Увеличение температуры приводит к смене знака коэффициента термоэдс с отрицательного на положительный при $T=240 \mathrm{~K}$ и коэффициент термоэдс достигает максимальных значений при $T=350 \mathrm{~K}$. Отличие в знаке коэффициентов Холла и термоэдс выше $275 \mathrm{~K}$ может быть связано с увлечением электронов фононами. Наличие орбитального упорядочения, как правило, приводит к сильному электрон-фононному взаимодействию.

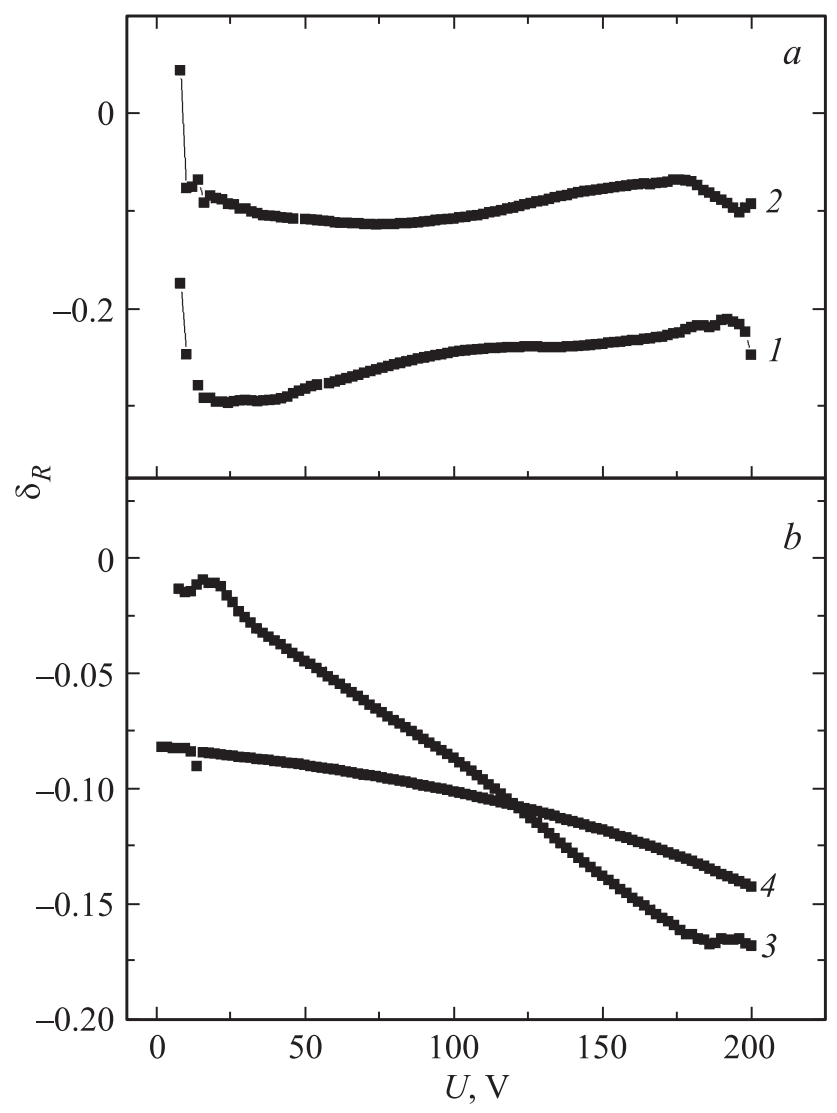

Рис. 3. Зависимость магнитосопротивления от напряжения, измеренная при $T=80(1), 160(2), 200$ (3), $280 \mathrm{~K}$ (4) для образца $\mathrm{Gd}_{0.2} \mathrm{Mn}_{0.8} \mathrm{Se}$.

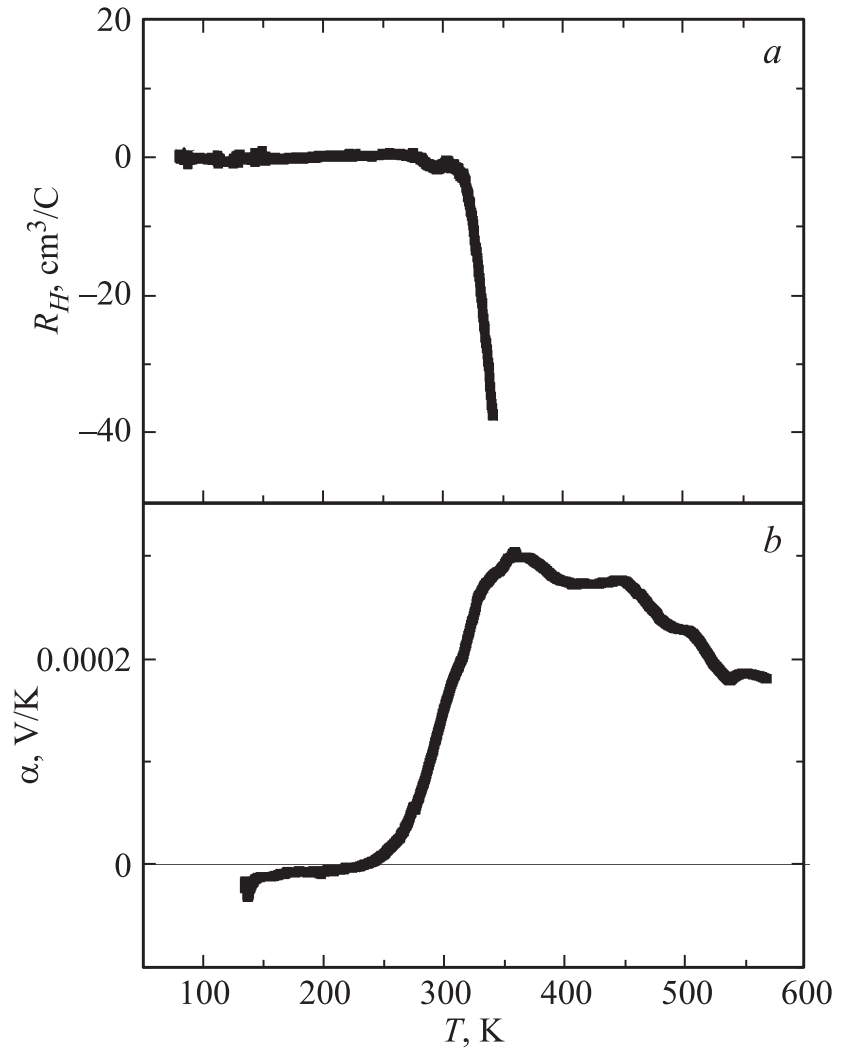

Рис. 4. Температурные зависимости константы Холла $(a)$ и коэффициента термоэдс $(b)$ для образца $\mathrm{Gd}_{0.2} \mathrm{Mn}_{0.8} \mathrm{Se}$.

Полученные нами данные по кинетическим свойствам халькогенидной системы показали, что в системе $\mathrm{Gd}_{0.2} \mathrm{Mn}_{0.8} \mathrm{Se}$ присутствуют два типа носителей заряда: дырки и электроны. При высоких температурах основными носителями заряда являются электроны, об этом свидетельствуют температурные зависимости константы Холла.

\section{3. Заключение}

В твердых растворах $\mathrm{Gd}_{x} \mathrm{Mn}_{1-x} \mathrm{Se}$ c $x=0.2$ на основе селенида марганца обнаружено уменьшение сопротивления в магнитном поле ниже $320 \mathrm{~K}$, так же как при анионном замещении теллуром. При высоких температурах сопротивление растет в магнитном поле. Экспериментальные данные объясняются образованием орбитального упорядочения и спин-орбитальным взаимодействием в модели Рашбы на интерфейсе ионов гадолиния и марганца. Обнаружен гистерезис вольтамперной характеристики, причиной которого является наличие орбитальных магнитных доменов и зависимость импульса электрона от спиновой поляризации.

В области температур с отрицательным магнитосопротивлением существует два типа носителей тока: электроны и дырки, с положительным магнитосопротивлением превалируют электроны. Наличие двух типов но- 
сителей заряда подтверждает данные термоэдс. Найдено различие знаков коэффицентов Холла и термоэдс выше комнатных температур, которое вызвано увлечением электронов фононами в результате электрон-фононного взаимодействия.

\section{Список литературы}

[1] S.S. Aplesnin, O.N. Bandurina, O.B. Romanova, L.I. Ryabinkina, A.D. Balaev, E.V. Eremin. J. Phys.: Condens. Matter 22, 226006 (2010).

[2] O.B. Romanova, L.I. Ryabinkina, V.V. Sokolov, A.Yu. Pichugin, D.A. Velikanov, D.A. Balaev, A.I. Galyas, O.F. Demidenko, G.I. Makovetskii, K.I. Yanushkevich. Solid State Commun. 150, 602 (2010).

[3] S.S. Aplesnin, O.B. Romanova, A.M. Harkov, D.A. Balaev, M.V. Gorev, A.M. Vorotinov, V.V. Sokolov, A.Yu. Pichugin. J. Phys. Status Solidi B 249, 812 (2012).

[4] С.С. Аплеснин, М.Н. Ситников. Письма в ЖЭТФ 100, 104 (2014).

[5] С.С. Аплеснин, М.Н. Ситников. ФТТ 58, 1112 (2016).

[6] S.S. Aplesnin, O.B. Romanova, K.I. Yanushkevich. Phys. Status Solidi B 252, 1792 (2015).

[7] D.L. Decker, R.L. Wild. Phys. Rev. B 4, 3425 (1971)

[8] S.-H. Wei, A. Zunger. Phys.Rev. B 48, 6111 (1993).

[9] S.J. Youn, B.I. Min, A.J. Freeman. Phys. Status Solidi B 241, 1411 (2004).

[10] Г.И. Маковецкий, А.И. Галяс. ФТТ 24, 2753 (1982).

[11] С.С. Аплеснин, Л.И. Рябинкина, О.Б. Романова, Д.А. Балаев, О.Ф. Демиденко, К.И. Янушкевич, Н.С. Мирошниченко. ФТT 49, 1984 (2007).

[12] А.В. Голубков, Е.В. Гончарова, В.П. Жузе, Г.М. Логинов, В.М. Сергеева, И.А. Смирнов. Физические свойства халькогенидов редкоземельных элементов. Наука, Л. (1973). $304 \mathrm{c}$.

[13] S.S. Aplesnin, A.I. Galyas, O.F. Demidenko, G.I. Makovetskii, A. Panasevich, K.I. Yanushkevich. Acta Phys. Pol. A 127, 371 (2015).

[14] M. Prasad, A.K. Pandit, T.H. Ansari, R.A. Singh. Mater. Chem. Phys. 30, 13 (1991).

[15] А.И. Галяс, О.Ф. Демиденко, Г.И. Маковецкий, К.И. Янушкевич, Л.И. Рябинкина, О.Б. Романова. ФТТ 52, 639 (2010).

[16] Э.И. Рашба. ФТТ 2, 1224 (1960).

[17] R. Peters, N. Kawakami, T. Pruschke. Phys. Rev. B 83, 125110 (2011).

[18] H. Vander Heide, C.F. van Briggen, C. Haas. Mater. Res. Bull. 18, 1515 (1983). 